\title{
REVISTA ENTRELÍNGUAS
}

Editorial, v. 4, n. 2, jul./dez. 2018

\section{EDITORIAL}

A Revista EntreLínguas: Ensino e Aprendizagem de Línguas Estrangeiras Modernas, vinculada ao Departamento de Letras Modernas da Faculdade de Ciências e Letras da Universidade Estadual Paulista "Júlio de Mesquita Filho" - Unesp - campus de Araraquara, chega a seu volume 4, número 2, com consideráveis conquistas. Em quatro anos, a EntreLínguas revelou-se de interesse internacional. Seu escopo central, o ensino e a aprendizagem de línguas estrangeiras modernas (LEM), tem chamado a atenção de pesquisadores de diferentes países. Em alguns casos, para além de acessarem a Revista, como podemos observar por meio do Clustrmaps, muitos pesquisadores têm contribuído como autores enviando artigos para avalição e publicação.

A visibilidade que a EntreLínguas está adquirindo no contexto de ensino e aprendizagem LEM no Brasil e em diferentes países tem sido fundamental para seu crescimento e aceitação tanto pelo meio acadêmico quanto pelas bases de dados, diretórios e indexadores (ABEC-Brasil, Sumários.Org., Latindex, Dialnet, BBE Biblioteca Brasileira de Educação, DOAJ, Edubase, DRJI, ERIHPLUS, CAPESperiódicos, entre outros).

O volume 4, número 2, dá continuidade, portanto, a esse trabalho de divulgação do conhecimento sobre o ensino e a aprendizagem de línguas estrangeiras modernas, contribuindo para a ampliação dos contextos de inserção da EntreLínguas. Dividido em três blocos que se unem no eixo do ensino e aprendizagem de LEM, o presente volume traz dez artigos de pesquisadores de diferentes Universidades brasileiras, bem como de Universidade estrangeira.

O primeiro bloco constitui-se como um conjunto de reflexões sobre o ensino e a aprendizagem para fins específicos. Em "Uma proposta de ensino-aprendizagem de inglês para fins específicos baseada no ensino híbrido”, Yna Honda de Sousa, Andréa Pereira Mendonça e Iandra Maria Weirich da Silva Coelho apresentam “uma proposta de 
ensino-aprendizagem de Inglês para Fins Específicos, denominada Blended English Teaching (BET), que combina ensino híbrido, recursos virtuais para estudo autônomo e um corpus compilado com textos autênticos, referentes a manuais e tutoriais de hardwares e softwares" cujos resultados apontam para um desempenho bastante produtivo, indicando que esse tipo de curso pode ser aplicado em outros contextos.

No segundo texto - Heterotônicos entre a língua portuguesa e a espanhola no âmbito das Ciências da Saúde", Ana María Díaz Ferrero aborda a sempre "problemática" semelhança entre as línguas portuguesa e espanhola no contexto de ensino de uma para falantes da outra como língua materna. Em seu texto, a autora propõe "uma classificação de heterotônicos" entre as línguas em questão e, empregando critérios semânticos e morfológicos de associação léxica, elabora um repertório lexicográfico de heterotônicos relativos à área das ciências da saúde.

Encerrando esse bloco, Jorge Armando Becerra-Callero e Angélica María RojasIsaza trazem uma discussão, além de atual, imprescindível para o momento histórico em que vivemos de internacionalização do conhecimento e inclusão. No texto "Ensino da Língua Inglesa para surdos desde uma perspectiva de práticas translíngues: motivações e intereresses", os autores analisam "os processos linguísticos e de assimilação que facilitaram a aprendizagem das estruturas básicas do inglês escrito em estudantes surdos.". Conclui-se, no estudo, que "não só se relacionam aspectos cognitivos ao processo de aprendizagem, senão que este envolve necessidades, usos, relações e adaptações aos novos conhecimentos.".

O segundo bloco, de temas mais variados, reúne reflexões em torno de questões como tecnologia, interferências linguísticas nos processos de ensino e de aprendizagem, materiais didáticos e Lexicografia Pedagógica. O primeiro texto, intitulado "Os desafios docentes e as contribuições das tecnologias educacionais no ensino e aprendizagem de língua inglesa: cenários contemporâneos", de Helenilson Ferreira de Sousa e Francisco Renato Lima, apresenta "uma visão acerca dos desafios dos educadores e as contribuições das tecnologias educacionais no ensino de Língua Inglesa (LI) na contemporaneidade e suas implicações no contexto escolar". Nesse panorama, os autores abordam questões como "o papel do livro didático, a abordagem sobre as Tecnologias da Informação e da Comunicação (TICs) no ensino de LI, a avaliação e a necessidade de formação continuada de professores".

Na sequência, em "Contribuições do Curso Online de Espanhol-Português para Intercâmbio (CEPI) na formação de professores de Português como Língua Adicional", 
de Gabriela da Silva Bulla, Kétina Allen da Silva Timboni, Mariana Bulegon e Raquel Horvath de Andrade, discute-se a formação de professores realizada no curso que dá nome ao artigo, vinculado ao Programa de Português para Estrangeiros (PPE), da Universidade Federal do Rio Grande do Sul (UFRGS). As autoras analisaram dados gerados na $10^{\mathrm{a}}$ edição do CEPI UFRGS, que explicitaram como o CEPI pode ser um espaço online de formação de professores.

Sobre influência da língua espanhola na aprendizagem de inglês trata o texto de Cristian Tugues Rodríguez. Sob o título "A influência do espanhol na aprendizagem do inglês em estudantes do Ensino Médio", apresentam-se no artigo reflexões sobre a "influência linguística que existe no ensino e aprendizagem das línguas estrangeiras". Considerando como contexto de pesquisa o ensino do inglês como língua estrangeira para falantes de espanhol como língua materna, o autor objetivou desenvolver nos estudantes e nos professores "consciência sobre tal fenômeno e entender que existe uma transferência negativa que deve ser solucionada". Os resultados confirmam, o que se afirma há algum tempo, que "a influencia e transferência são aspetos de grande importância na aprendizagem de segundas línguas e, já seja positivo ou negativo, o professor deve ter em conta a forma de se beneficiar" desse fenômeno ou se opor a ele.

$\mathrm{O}$ terceiro texto deste conjunto aborda a questão dos sentidos silenciados em materiais didáticos. De autoria de Joelma Aparecida Bressanin e Simone Miller da Silva Campos, propõe-se no texto "Sentidos silenciados em materiais didáticos de língua inglesa" "compreender como os materiais didáticos, destinados ao ensino da língua inglesa, levam em consideração a relação entre língua, sujeito e história (ideologia) e em que medida a prática de linguagem se configura nesses materiais". As autoras, a partir do aporte teórico da Análise do Discurso de linha francesa, observam "que as culturas dos países de língua inglesa não são abordadas de maneira satisfatória, pois, muitas vezes, enfatiza-se apenas a cultura dos países hegemônicos, como Estados Unidos e Inglaterra, contribuindo para o trabalho de homogeneização linguística e visando uma ação mercadológica dos produtos euro-americanos".

$\mathrm{O}$ quarto texto, de caráter mais teórico, traz uma reflexão sobre uma área em relevante crescimento no Brasil: a Lexicografia Pedagógica. Raissa Adorno de Oliveira e Odair Luiz Nadin, em "Seleção e análise de contextos de uso em corpora de língua espanhola: reflexões sobre candidatos a exemplos lexicográficos", descrevem o processo de seleção e análise de contextos a fim de que possam servir como exemplos lexicográficos em um dicionário pedagógico bilíngue de espanhol para aprendizes 
brasileiros. Os autores apresentam "os processos de seleção e análise dos contextos, demonstram como se deu a coleta dos contextos nos corpora, a elaboração de critérios para a análise e a verificação da pertinência ou não dos contextos para o dicionário.”.

Encerrando o presente número da EntreLínguas (volume 4, número 2), temos dois Relatos de Experiência. No primeiro, intitulado "PIBID: O ensino dos estrangeirismos por meio da aprendizagem baseada em problemas", Alana Gabriele da Silva, Carlos Vinícius Olímpio, Lívia Carolina Baenas Barizon apresentam uma proposta de "sequência didática sobre a utilização dos estrangeirismos, aplicada no subprojeto de Letras Português, a qual consistiu no uso da metodologia ativa da aprendizagem baseada em problemas, que modificou o ensino tradicional dando espaço para a produção do conhecimento autônomo e com significado".

O segundo, "Possibilidades para o ensino de língua inglesa na Era Pós-Método: um Relato de Experiência de Estágio", Daniele Carla De Morais e Fernanda Sanches Busch relatam que a experiência de ensino de língua inglesa a partir dessa perspectiva teóricometodológica "levou a uma prática que foi considerada significativa pelas professoras em formação envolvidas, pois as atividades foram realizadas pelos alunos e pelas alunas com perceptível motivação e engajamento".

Assim, o presente número da EntreLínguas traz relevantes contribuições tanto para o ensino e a aprendizagem de línguas estrangeiras modernas propriamente ditos quanto para questões que alcançam outros níveis de reflexões como o contexto de ensino de língua inglesa para surdos, por exemplo. A EntreLínguas cumpre, desse modo, um relevante papel no moderno mundo das tecnologias que somente alcançará por completo seus objetivos se se considerar a inclusão e a democratização dos saberes.

Odair Luiz NADIN Andreia C. Roder CARMONA-RAMIRES Editores/Organizadores v. 4, n. 2, jul./dez. 2018 